\title{
Catalytic conversion of methanol to larger organic molecules over crystalline forsterite: laboratory study and astrophysical implications
}

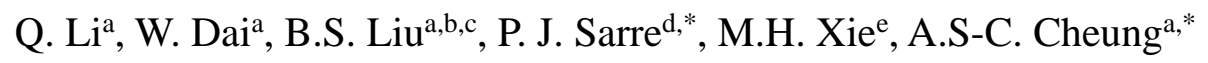

a Department of Chemistry, The University of Hong Kong, Pokfulam Road, Hong Kong,

China.

${ }^{\mathrm{b}}$ Department of Chemistry, Tianjin University, Tianjin 300072, China.

${ }^{\mathrm{c}}$ The National Collaborative Innovative Center of Chem. Sci. Eng. Tianjin, Tianjin 300072,

China.

${ }^{\mathrm{d}}$ School of Chemistry, The University of Nottingham, University Park, Nottingham NG7 2RD, United Kingdom

${ }^{\mathrm{e}}$ Department of Physics, The University of Hong Kong, Pokfulam Road, Hong Kong.

Keywords: Astrochemistry; catalysis; crystalline silicate; methanol; PAHs; TOF-MS; DFT Proposed running head: Catalytic conversion of methanol

*Corresponding author:

Email address: peter.sarre@ nottingham.ac.uk (P.J. Sarre)

Professor Peter J. Sarre

School of Chemistry

The University of Nottingham

University Park

Nottingham NG7 2RD

United Kingdom

Tel : (44) 1159513450

Email : peter.sarre@nottingham.ac.uk

Email addresses: u3002724@ connect.hku.hk (Q. Li), crystaldaiasn@gmail.com (W. Dai), bingsiliu@tju.edu.cn (B.S. Liu), peter.sarre@nottingham.ac.uk (P.J. Sarre), mhxie@ @hku.hk (M.H. Xie), hrsccsc@hku.hk (A. Cheung).

Text : 24

Figures : 5

Schemes : 3

Tables : 2 


\section{ABSTRACT}

Laboratory catalytic reactions of methanol over heated crystalline silicates (forsterite) lead to the formation of gas-phase olefinic and polycyclic aromatic hydrocarbon (PAH) molecules, and are of potential importance in astrophysical environments including hot molecular cores, protoplanetary disks and shocks. In our experiments the methanol reagent, together with intermediate and product gas-phase molecular species were detected using time-of-flight mass-spectrometry (TOF-MS). A solid deposited on the crystalline forsterite surface was examined subsequently using high-resolution transmission electron microscopy and thermal gravimetric techniques and found to comprise amorphous and graphitic carbon. The chemical players in this work - gas-phase methanol, crystalline silicates and PAHs, have been identified spectroscopically in a range of astrophysical environments including young and evolved stars, protoplanetary disks, comets, captured dust particles and meteorites. It is envisaged that reactions on bare dust grains as studied here both experimentally and theoretically through DFT calculations, can have implications for chemical transformations and conversions, in forming PAH molecules and potentially in the synthesis of prebiotic molecules. 


\section{Introduction:}

Gas-surface reactions and large molecule formation processes of relevance in astrophysical environments have been studied for many years (Minh and van Dishoeck 2000;

Herbst 2005; Herbst and van Dishoeck 2009; Tielens 2013; Schlemmer et al. 2014; van Dishoeck 2014; Williams \& Cecci-Pestellini 2016; Herbst 2017). Physical conditions differ widely, ranging in temperature from a few $\mathrm{K}$ in dense clouds with dust grains predominantly covered by ices, to warm protostellar regions, shocks, circumstellar envelopes (CSEs), and diffuse clouds with mainly bare grain surfaces. In order to understand chemical reactions occurring on dust grains, in general both physisorption and chemisorption processes need to be considered. Physisorption is a weak interaction and is of significance only at very low temperatures; chemisorption on a surface is generally stronger, and an important initial step in a heterogeneous catalytic reaction.

Many reactions on the surfaces of bare interstellar grain analogues (including silicates) have been studied, with particular emphasis on molecular hydrogen formation (Schlemmer et al. 2014; Williams \& Cecci-Pestellini 2016; for a recent review see Wakelam et al. 2017). Herbst et al. (2005) reported theoretical studies of chemical reactions on interstellar grains and verified efficient formation of $\mathrm{H}_{2}$ from atomic hydrogen over a wide temperature range on inhomogeneous surfaces. The formation of molecular hydrogen specifically on silicates has been studied in detail with the rotational population distribution of $\mathrm{H}_{2}$ determined 
(Williams \& Cecci-Pestellini 2016; Sabri et al. 2014; Gavilan et al. 2014). Reactions involving atoms other than hydrogen include work described by Anders et al. $(1973,1974)$ who reviewed the catalytic reactions of $\mathrm{CO}, \mathrm{H}_{2}$ and $\mathrm{NH}_{3}$ on silicate and carbonate grain surfaces leading to the formation of small organic molecules as found in meteorites, the products including alcohols, aldehydes, ketones, ethers and esters. Ferrante et al. (2000) studied catalytic gas-grain surface reactions of $\mathrm{CO}$ on Fe-doped silicates producing methane, ethane, ethylene, $\mathrm{CO}_{2}$ and $\mathrm{H}_{2} \mathrm{O}$. Kress \& Tielens (2001), using kinetic model calculations, confirmed that Fischer-Tropsch catalysis plays an important role in solar nebula chemistry by converting $\mathrm{CO}$ to less volatile hydrocarbons. Our own earlier laboratory studies (Tian et al. 2012, 2013; Zhao et al. 2016) have shown that olivine-type silicates, pyroxene, alumina and $\mathrm{SiC}$ particles can promote the conversion of acetylene gas to polycyclic aromatic hydrocarbons (PAHs).

In this paper we focus on the relation between our methanol/forsterite experimental studies and the composition, morphology and conditions of young stellar environments including hot molecular cores, protoplanetary disks, pre-main-sequence Herbig Ae/Be and $\mathrm{T}$ Tauri stars, and shocked regions. As discussed in Section 4, the astrophysical coexistence of methanol (commonly from ice mantles), bare crystalline forsterite grains and PAH emission indicates a strong synergy with our experimental results. It is noted that in using the term 'forsterite' it is not suggested that the sample used here is pure $\mathrm{Mg}_{2} \mathrm{SiO}_{4}$. 
Analysis of the catalytic surface described in section 2.2 shows that $\mathrm{Fe}$ (which can replace

$\mathrm{Mg}$ in the crystal) is present at about the $2 \%$ level and probably plays a very significant role in the catalytic reactions. As far as we are aware, this work provides the first direct experimental evidence that methanol can participate in catalytic reactions on bare crystalline forsterite forming olefin and PAH molecules.

\section{Experimental}

\subsection{Apparatus and experimental conditions:}

The time-of-flight mass-spectrometer (TOF-MS) used in this work has been discussed in detail in earlier publications (Tian et al. 2012, 2013; Zhao et al. 2016) so only a brief description of the equipment and experimental conditions is given here. This home-built instrument consists of a source chamber with a quartz tube fixed-bed reactor, an ionization chamber, a flight tube and a detection chamber. A feeding device is connected to the reactor and the reactant gas is introduced via an electronically controlled pulsed valve and passes through the reactor containing the solid sample. The neutral gas-phase products of the gassurface reactions are directed into an ionization chamber through a 2-mm diameter skimmer, and ions are generated using laser radiation from an ArF excimer laser operating at $193 \mathrm{~nm}$. The ions are accelerated and focussed by a lens assembly and travel through a 1-metre TOF field-free region before reaching a multi-channel plate (MCP) detector. The signals from the MCP detector are collected and forwarded to a $300 \mathrm{MHz}$ oscilloscope for averaging and 
storage.

In the experiments reported here about $100 \mathrm{mg}$ of forsterite was placed inside the quartz tube reactor and pretreated to $600{ }^{\circ} \mathrm{C}$ in flowing argon to remove any residual gas on the surface. Methanol vapour was introduced in pulsed mode to the reactor at a repetition rate of $10 \mathrm{~Hz}$, and the catalytic reaction of methanol was carried out in a temperature range between 400 and $700{ }^{\circ} \mathrm{C}$. A solid deposit generally appeared on the silicate surface which was analyzed subsequently by surface analytical techniques.

\subsection{Characterization of the forsterite using HRTEM, FT-IR and TG/DTG techniques}

The forsterite used in this work was provided by the Geological Museum of the University of Hong Kong, and its structure and physical properties before reaction have been reported earlier (Tian et al. 2012). After reaction, an HRTEM image of the solid was obtained using a TECNAL G2 F20 electron microscope, and thermal gravimetric (TG) analysis was performed using a NETZSCHSTA 409 PC/PG thermogravimetric analyzer. The crystalline sample contains $c$. $1.8 \%$ Fe which, as discussed later is important in promoting the methanol/surface reactions. Analysis of a crystalline forsterite emission feature at or near $69.7 \mu \mathrm{m}$ in spectra of protoplanetary disks has constrained the iron content of the forsterite to be at most a few percent (Sturm et al. 2013) - a value not dissimilar to the iron $\%$ for the experimental sample used in this work. 
Adsorption of methanol on the surface prior to reaction was examined using a Nicolet 6700 infrared spectrophotometer with an attenuated total reflectance (ATR) assembly. Adsorption of methanol at $1.8 \mathrm{bar}, 0.3 \mathrm{bar}$ and at the saturated vapour pressure of methanol was examined, and an ATR-FTIR spectrum between 400 and $4000 \mathrm{~cm}^{-1}$ recorded. The TG profile of the weight loss of carbon deposited on the forsterite surface was obtained by heating the (post-reaction) crystals at a rate of $10{ }^{\circ} \mathrm{C} / \mathrm{min}$ in air up to $700{ }^{\circ} \mathrm{C}$.

\section{Results and discussion}

\subsection{TOF-MS analysis of methanol conversion}

TOF mass spectra of the methanol (parent $\mathrm{m} / \mathrm{z}=32$ ) conversion after various times onstream at $550{ }^{\circ} \mathrm{C}$ are shown in Figure 1 . It is seen that when the reaction began, low ion signals at $\mathrm{m} / \mathrm{z}=1,2,12,15,16,18,28,39$ and 44 appeared, the peak with $\mathrm{m} / \mathrm{z}=32$ (methanol cation) was negligible, and only very weak signals for $\mathrm{m} / \mathrm{z}>60$ were observed. This indicates that a considerable number of gas-phase methanol molecules were adsorbed on the forsterite surface and also that low-mass volatile reaction products were released from the surface. The TOF-MS signals at $\mathrm{m} / \mathrm{z}=18,28,39$ and 44 can be attributed to the formation of the $\mathrm{H}_{2} \mathrm{O}^{+}, \mathrm{CO}^{+}$(or $\mathrm{C}_{2} \mathrm{H}_{4}{ }^{+}$), $\mathrm{C}_{3} \mathrm{H}_{3}{ }^{+}$and $\mathrm{CO}_{2}{ }^{+}$(or $\mathrm{CH}_{3} \mathrm{CHO}^{+}$) and the signals at $\mathrm{m} / \mathrm{z}=1,12,15$ and $16\left(\mathrm{H}^{+}, \mathrm{C}^{+}, \mathrm{CH}_{3}{ }^{+}\right.$and $\left.\mathrm{O}^{+}\right)$are associated with the laser ionization/fragmentation of the aforementioned molecules.

The TOF-MS signals at $\mathrm{m} / \mathrm{z}=27,28,37,39,44,50,51$, and 63 grow with time (Figure 
1). When the reaction time was about 15 minutes, the initially adsorbed methanol molecules combined and then released to form the $\mathrm{C}_{2} \mathrm{H}_{4}, \mathrm{CO}, \mathrm{CH}_{3} \mathrm{CHO}$ and $\mathrm{CO}_{2}$ species as well as the following intermediates and radicals: $\mathrm{C}_{2} \mathrm{H}_{3}, \mathrm{C}_{3} \mathrm{H}, \mathrm{C}_{3} \mathrm{H}_{3}, \mathrm{C}_{4} \mathrm{H}_{2}, \mathrm{C}_{4} \mathrm{H}_{3}, \mathrm{C}_{5} \mathrm{H}_{3}$ as detected through their ion signals. According to the reaction mechanism proposed in our earlier work (Tian et al. 2012), these molecules and intermediates further couple to form benzene, naphthalene and polycyclic aromatic hydrocarbons on the Lewis acid sites of the forsterite as shown most clearly in the longer (later) time TOF-MS spectra in Fig. 1. After the reaction had proceeded for about $50 \mathrm{~min}$, the signals of $\mathrm{C}_{2} \mathrm{H}_{3}{ }^{+}, \mathrm{CO}_{2}{ }^{+}$and the low-mass hydrocarbon signals gradually declined; the presence of signals from $\mathrm{CH}_{3} \mathrm{OH}$ and its associated species $(\mathrm{m} / \mathrm{z}=29,31$ and the parent 32$)$, indicates that adsorption of methanol on the surface had slowed due to the deactivation of the catalyst. The uppermost spectrum in Figure 1. is in fact very similar to the standard electron impact mass spectrum of gaseous methanol. From the temperature- and time-dependence of the methanol conversion, we found that the most favourable conditions for forming high-mass hydrocarbons and PAHs in this experiment were a temperature of around $600{ }^{\circ} \mathrm{C}$ and about 10 minutes after the reaction started. Figure 2 shows a comparison of the formation of the products as a function of time. The lowermass hydrocarbons $(\mathrm{m} / \mathrm{z}=39,51$ and 63$)$ were produced in much higher quantity than the higher mass PAHs $(\mathrm{m} / \mathrm{z}=128,178$ and 202). A full list of the species identified for the catalytic reaction of methanol on forsterite is given in Table 1. 
In order to further confirm the molecular species arising from the catalytic methanol reactions, deuterated methanol-d4 (99.8\% deuterated) was used. Figures 3a and 3b show the TOF-MS signals obtained at $600{ }^{\circ} \mathrm{C}$ using methanol and methanol-d4 respectively (for $\mathrm{m} / \mathrm{z}$ signals $>90$ they have been scaled up by a factor of 2). Reaction intermediates, radicals and products identified are listed in Table 1 . The signal at $\mathrm{m} / \mathrm{z}=28 \mathrm{can}$ be assigned to $\mathrm{CO}$ or $\mathrm{C}_{2} \mathrm{H}_{4}$, and $\mathrm{m} / \mathrm{z}=44$ to $\mathrm{CO}_{2}$ or $\mathrm{CH}_{3} \mathrm{CHO}$ molecules, as shown in Figure 3 ; the result verified that the aforementioned signals originated from the $\mathrm{CO}$ and $\mathrm{CO}_{2}$ species as the intensity of the peaks was the same in both deuterated and normal methanol spectra (Figures $3 \mathrm{a}$ and $3 \mathrm{~b}$ ). However, for the $\mathrm{C}_{2} \mathrm{H}_{4}$ and $\mathrm{CH}_{3} \mathrm{CHO}$ molecules, the signals should be observed with a corresponding shift of 4 mass units in the deuterated methanol spectrum. The strong signals at $\mathrm{m} / \mathrm{z}=27\left(\mathrm{C}_{2} \mathrm{H}_{3}{ }^{+}\right)$- straightly derived from the $\mathrm{C}_{2} \mathrm{H}_{4}$ due to low ionization energy, $37\left(\mathrm{C}_{3} \mathrm{H}^{+}\right), 39\left(\mathrm{C}_{3} \mathrm{H}_{3}^{+}\right), 51\left(\mathrm{C}_{4} \mathrm{H}_{3}{ }^{+}\right)$and $63\left(\mathrm{C}_{5} \mathrm{H}_{3}^{+}\right)$in the methanol spectrum shift to $\mathrm{m} / \mathrm{z}=30\left(\mathrm{C}_{2} \mathrm{D}_{3}^{+}\right), 38\left(\mathrm{C}_{3} \mathrm{D}^{+}\right), 42\left(\mathrm{C}_{3} \mathrm{D}_{3}^{+}\right), 54\left(\mathrm{C}_{4} \mathrm{D}_{3}{ }^{+}\right)$and $66\left(\mathrm{C}_{5} \mathrm{D}_{3}^{+}\right)$in the mass spectrum obtained using methanol-d4 as reactant (Figure 3b). Similarly, the PAHs identified earlier, such as naphthalene $(\mathrm{m} / \mathrm{z}=128)$, the fluorenyl radical $(165)$ and pyrene (202) are also mass-shifted in the corresponding deuterated compound as expected. Concerning the strongest TOF-MS signal (Figure 3) at $\mathrm{m} / \mathrm{z}=39$ (42 for the deuterated form), it can be assigned to the $\mathrm{C}_{3} \mathrm{H}_{3}{ }^{+}\left(\mathrm{C}_{3} \mathrm{D}_{3}{ }^{+}\right)$cation which has two structural forms: cyclic- $\mathrm{C}_{3} \mathrm{H}_{3}{ }^{+}\left(c-\mathrm{C}_{3} \mathrm{H}_{3}{ }^{+}\right)$and linear- $\mathrm{C}_{3} \mathrm{H}_{3}{ }^{+}\left(l-\mathrm{C}_{3} \mathrm{H}_{3}{ }^{+}\right)$and their structures have been reported 
extensively in the literature (Fahr et al. 2005; Ricks et al. 2010; Huang \& Lee 2011; Ali et al. 2013). The $c-\mathrm{C}_{3} \mathrm{H}_{3}{ }^{+}$cation has been detected in the Titan's upper atmosphere (Ali et al. 2013) and is more stable than the $l-\mathrm{C}_{3} \mathrm{H}_{3}{ }^{+}$form by $c .113 \mathrm{kJmol}^{-1}$. A laboratory spectrum of gas-phase $c-\mathrm{C}_{3} \mathrm{H}_{3}{ }^{+}$has been reported (Zhao et al. 2014) which should facilitate a search for this molecule in interstellar clouds and protostellar environments.

However, using the TOF-MS technique alone, we are not be able to determine the structural form of the $\mathrm{C}_{3} \mathrm{H}_{3}{ }^{+}$isomers.

\subsection{PAH species and carbon deposition on the silicate surface}

As shown in Figure 1, after the reaction was allowed to proceed for $50 \mathrm{~min}$, the amount of methanol converted was very low, leaving mainly gas-phase methanol and its fragment ion signals to be detected. The forsterite surface was covered with a black colour deposit which blocked the active sites and was responsible for deactivation of the catalyst. An HRTEM image was taken to examine the characteristics of the deposit. As shown in Figure 4a, a considerable amount of fibre-like carbon structure with a diameter of 40-80 nm was observed and when the dark spot in Figure 4a was magnified it showed a multi-layered graphene structure or parallel amorphous carbon layers on the surface with a size of $c a .30$ $\mathrm{nm}$ (Fig. 4b and 4c), similar to the observation of acetylene conversion to PAHs over SiC grains (Zhao et al. 2016). As reported in our earlier publication (Tian et al. 2013), large PAHs such as fluorenyl radicals $(\mathrm{m} / \mathrm{z}=165)$, pyrene $(\mathrm{m} / \mathrm{z}=202)$ and benzo[b]fluorene $(\mathrm{m} / \mathrm{z}$ 
$=215$ ) could remain on the surface. With increase in time on stream, these PAHs sustain growth on the forsterite grains to form multi-layered graphene or carbon nanotubes (CNTs).

Figure $4 \mathrm{~d}$ shows the thermal gravimetric (TG) profiles of the carbon deposit. An analysis of the TG weight loss of carbon deposition indicates (i) trace amounts of physically adsorbed water $\left(200{ }^{\circ} \mathrm{C}\right)$, (ii) hydrogenated carbon of the form $\mathrm{C}_{\mathrm{x}} \mathrm{H}_{\mathrm{y}}$ including large PAHs $(0.5 \%, 345$ $\left.{ }^{0} \mathrm{C}\right)$, (iii) graphene or graphitic structures $\left(0.5 \%, 455{ }^{\circ} \mathrm{C}\right)$ and (iv) carbon nanotubes (CNTs) (1\%, above $600{ }^{\circ} \mathrm{C}$ ) (Guo et al. 2014); the aforementioned carbon species on the forsterite surface were oxidized into $\mathrm{CO}_{2}$ and removed from the surface at a different temperatures.

\subsection{Pathway for conversion of methanol to olefins.}

As discussed earlier, catalytic conversion of methanol forms initially $\mathrm{H}_{2} \mathrm{O}, \mathrm{CO}_{2}$ and $\mathrm{CO}$, olefins, and then eventually PAHs. We propose the reaction proceeds with methanol adsorption on the olivine surface as an initial step (Scheme 1), and two different intermediate pathways: (i) formation of olefins and $\mathrm{H}_{2} \mathrm{O}$ (Scheme 2) and (ii) formation of $\mathrm{CO}_{2}$ and $\mathrm{CO}$ (Scheme 3) and, finally, (iii) production of PAHs. It is recognised that while reactions involving methanol molecules alone are appropriate in interpreting the experimental results presented here, in astrophysical environments other molecules such as $\mathrm{H}_{2} \mathrm{O}$ and $\mathrm{CO}$ together with methanol could also be significant and further experimental studies are warranted. 
Chemisorption is the initial step in any catalytic reaction, and the adsorbed molecule must undergo bond cleavage at various positions leading to the formation of reactive intermediate species which drive the reaction. In this work, we consider the interaction between the methanol molecule and metal ( $\mathrm{Mg}$ and $\mathrm{Fe}$ ) and silicon atoms on the forsterite surface. Using density functional theory (DFT), the adsorption energy of the methanol molecule on the surface was calculated; the specific interaction between the atoms in methanol and those on the surface was studied by arranging the methanol molecule in various configurations. The structural changes of the methanol molecule were examined to identify bonds that are weakened as a result of the adsorption process. A weakened bond can lead to bond cleavage and the formation of reactive intermediates which promote the formation of products. As shown in Scheme 1, the methanol molecules are allowed to be adsorbed on the (100) plane of $\mathrm{Fe}_{2} \mathrm{SiO}_{4}$ or $\mathrm{Mg}_{2} \mathrm{SiO}_{4}$ in five different configurations (orientations). The adsorption energy and bonding parameters of methanol were calculated using the Vienna Ab Initio Simulation Package (VASP) (Kresse and Hafner 1993; Kresse and Furthmüller 1996); due to the practical limitations of the software package, the calculations were performed by treating the silicate surface as pure $\mathrm{Mg}_{2} \mathrm{SiO}_{4}$ and pure $\mathrm{Fe}_{2} \mathrm{SiO}_{4}$ separately. The results obtained are summarized in Table 2. It can be seen that the adsorption energy is low $(16.9-46.3 \mathrm{~kJ} / \mathrm{mol})$ for the hydrogen interaction between $\mathrm{CH}_{3} \mathrm{OH}$ and an oxygen atom on the surface (Model I in Scheme 1) so it is not likely to form a stable 
adsorption complex. However, direct interaction between the oxygen atom in methanol and an Fe (or Mg) or Si atom on the surface (Models II and IV in Scheme 1) is much stronger, especially for the $\mathrm{Si}$ atom with an adsorption energy of $102.5 \mathrm{~kJ} / \mathrm{mol}$ (Table 2). The synergistic action between $\mathrm{O}$ and $\mathrm{H}$ atoms in methanol on the surface is highly favourable for methanol adsorption (Model III and V in Scheme 1). Consequently, we propose a reaction mechanism for the conversion of methanol to $\mathrm{C}_{2} \mathrm{H}_{4}$ (olefins) and production of $\mathrm{H}_{2} \mathrm{O}$ as summarized in Scheme 2, where a methanol molecule is adsorbed on the surface via the synergistic action of oxygen in methanol with surface Fe as well as hydrogen with subsurface oxygen (Model III in Scheme 1). Simultaneously, another methanol molecule approaches the silicon atom next to the Fe atom (Model V in Scheme 1). Based on the calculation results in Table 2, the adsorption energy of the methanol to the Fe-O bond (73.5 $\mathrm{kJ} / \mathrm{mol})$ is far lower than that for the $\mathrm{Si}-\mathrm{O}$ bond $(183.8 \mathrm{~kJ} / \mathrm{mol})$. Subsequently, a significant elongation of the $\mathrm{O}-\mathrm{H}$ bond (from $0.0972 \mathrm{~nm}$ to $0.1013 \mathrm{~nm}$ ) in the former case, leads to bond cleavage and formation of a $\mathrm{CH}_{3}-\mathrm{O}-\mathrm{Fe}$ adsorption complex and $\mathrm{H}-\mathrm{OSi}$ at the Brönsted acid sites. In contrast, a large elongation of the $\mathrm{O}-\mathrm{CH}_{3}$ bond (from $0.1432 \mathrm{~nm}$ to $0.1458 \mathrm{~nm}$ ) and the large binding energy of Si-O $(183.8 \mathrm{~kJ} / \mathrm{mol})$ results in breaking of the $\mathrm{C}-\mathrm{O}$ bond of O- $\mathrm{CH}_{3}$ to produce an $\mathrm{HO}-\mathrm{Si}$ group and a methyl cation $\left(\mathrm{CH}_{3}{ }^{+}\right)$, which subsequently attacks the oxygen atom on $\mathrm{CH}_{3}-\mathrm{O}-\mathrm{Fe}$ to form an unstable transition complex $\mathrm{CH}_{3}-\mathrm{OCH}_{3}: \mathrm{Fe}$ (Model II in Scheme 2). This transition complex undergoes cleavage of the O-Fe bond 
(binding energy $73.5 \mathrm{~kJ} / \mathrm{mol}$ ) as well as formation of $\mathrm{CH}_{2}=\mathrm{CH}_{2}$ and $\mathrm{H}_{2} \mathrm{O}$ (Model III in Scheme 2). As noted in Figure 1, in addition to $\mathrm{C}_{2} \mathrm{H}_{4}{ }^{+}, \mathrm{a} \mathrm{C}_{2} \mathrm{H}_{3}{ }^{+}(\mathrm{m} / \mathrm{z}=27)$ species was also rapidly formed. Furthermore, $\mathrm{H}_{2} \mathrm{O}^{+}$was made at the initial conversion stage of methanol on the surface.

The above bond weakening processes are consistent with the vibrational frequency shifts between the adsorbed and gas-phase methanol. FT-IR spectra obtained before and after methanol adsorption provide good support for the proposed reaction mechanism. When the forsterite surface was exposed to 0.35 and 1.8 bar (Fig. 5b-c) of methanol, it can be seen that there is no appreciable variation in the FT-IR spectra as compared to only the solid forsterite (Fig. 5a). However, in the case of the forsterite surface exposed to saturated methanol vapour, as shown in Fig. 5d, the vibrational band at $3319 \mathrm{~cm}^{-1}$ is attributed to the $\mathrm{O}-\mathrm{H}$ stretching vibration of the adsorbed methanol, which is shifted $33 \mathrm{~cm}^{-1}$ to lower wavenumber compared with pure methanol $\left(3352 \mathrm{~cm}^{-1}\right)$, and is due to elongation of the O$\mathrm{H}$ bond (Table 2). Similarly, the C-O stretching vibration band for the adsorbed methanol is lowered by $10 \mathrm{~cm}^{-1}$ (from 1032 to $1022 \mathrm{~cm}^{-1}$ ) and is due to the formation of $\mathrm{CH}_{3} \mathrm{OH}-\mathrm{Fe}$ (or $\mathrm{Mg}$ ) or $\mathrm{CH}_{3} \mathrm{OH}-\mathrm{Si}$ adsorption complexes. Furthermore, the stretching vibration bands associated with the $-\mathrm{CH}\left(2832 \mathrm{~cm}^{-1}\right)$ and $-\mathrm{CH}_{3}\left(2945 \mathrm{~cm}^{-1}\right)$ groups of the adsorbed methanol are almost the same as for pure gas-phase methanol.

It is also noted that in the early stages of the reaction, the methanol conversion could 
also undergo an alternative reaction pathway for forming $\mathrm{CO}_{2}$ and $\mathrm{CO}$ as described in Scheme 3. A methanol molecule is adsorbed on the surface via the interaction of the $\mathrm{O}$ atom on methanol with a top-layer Si atom (Model IV of Scheme 1); simultaneously another methanol molecule approches the Fe atom that is adjacent to a $\mathrm{Si}$ atom and co-adsorption of $\mathrm{O} / \mathrm{H}$ atoms in methanol occurs (Model III in Scheme 1). From the calculation results, significant elongation of the O-H $(0.1013 \mathrm{~nm})$ and $\mathrm{C}-\mathrm{O}(0.1463 \mathrm{~nm})$ bonds leads preferentially to the cleavage of $\mathrm{O}-\mathrm{H}$ and $\mathrm{C}-\mathrm{O}$ bonds to form the $\mathrm{CH}_{3}{ }^{+}$ion and $\mathrm{HO}-\mathrm{Fe}$ acid sites, while the $-\mathrm{CH}_{3}$ group in the $\mathrm{CH}_{3} \mathrm{O}-\mathrm{Fe}$ complex attacks the $\mathrm{O}$ atom in the $\mathrm{H}-\mathrm{OSi}$ intermediate complex and is accompanied by the release of $\mathrm{H}_{2}$ (Model II in Scheme 3). Compared with $\mathrm{Fe}_{2} \mathrm{SiO}_{4}$, the methanol adsorption on the $\mathrm{Mg}_{2} \mathrm{SiO}_{4}$ surface is much weaker, indicating that the small amount ( $\sim 2 \%$ by atom) of $\mathrm{Fe}$ in the forsterite sample is crucial. Subsequently, the adsorbed formadehyde species is dehydrogenated to produce an $\mathrm{H}^{+}$ion and the formate. Therefore, the observed $\mathrm{CO}_{2}{ }^{+}$and $\mathrm{H}^{+}$signals in the TOF-MS spectrum (Fig. 1) can be attributed to the decomposition of formate from the HCOO-Si (Model III in Scheme 3). On the other hand, the aforementioned adsorbed complex generates the $\mathrm{CH}_{3} \mathrm{OCHO}$ molecule by the addition of a $-\mathrm{CH}_{3}$ group to the $\mathrm{CH}_{3} \mathrm{OH}-\mathrm{Si}$ complex on the oxygen atom in the $\mathrm{CH}_{3} \mathrm{O}-\mathrm{Fe}$ complex (Model IV in Scheme 3), and the $\mathrm{CH}_{3} \mathrm{OCHO}$ can then decompose to produce $2 \mathrm{CO}$ and $2 \mathrm{H}_{2}$, which were observed clearly at the initial stage of the reaction. 
For the eventual formation of PAHs by coupling the hydrocarbon compounds formed as intermediates, the methylation and dehydrogenation of $\mathrm{CH}_{2}=\mathrm{CH}_{2}$ by methanol is responsible for the formation of propyne $\mathrm{CH}_{3} \mathrm{C} \equiv \mathrm{CH}$ or $\mathrm{CH}_{2}=\mathrm{C}=\mathrm{CH}_{2}(\mathrm{~m} / \mathrm{z}=40)$ molecules and with enhancement of the propargyl radical $(\mathrm{m} / \mathrm{z}=39)$. It has been shown by Li et al. (2008) that a mixture of methanol and unsaturated hydrocarbons can enhance the production of longer chain hydrocarbon compounds. In that work, using pre-coked ZSM-22 as the catalyst, in which the conversion of methanol or ethene alone is low, it was found that if methanol and ethene were cofed together, higher than $80 \%$ propene selectivity was achieved. Similar effects could also be involved in enhancing the conversion in this work. Further methylation of $\mathrm{CH}_{2}=\mathrm{C}=\mathrm{CH}_{2}$ by methanol with dehydrogenation generates compounds like 1-buten-3-yne $(\mathrm{m} / \mathrm{z}=52)$. When the number of carbon atoms is more than 6 , the aliphatic hydrocarbon chain could cyclicize spontaneously to form benzene, naphthalene and many other PAHs (Liu et al. 2011). Reactions involving methanol molecules alone are appropriate in interpreting the experimental results presented here. However, in astrophysical environments reactions involving other molecules such as $\mathrm{H}_{2} \mathrm{O}$ and $\mathrm{CO}$ together with methanol could also be significant and might give rise to important synergistic effects as found in the laboratory for methanol/ethene mixtures. Further experimental and theoretical studies including more than one type of molecule are warranted. 


\section{Astrophysical considerations}

\subsection{Evolved stars}

Our earlier experimental studies (Tian et al. 2012, 2013; Zhao et al. 2016) focussed on reactions involving acetylene on surfaces that are likely of most significance in carbon-rich circumstellar envelopes (CSEs) of late-type stars and mixed-chemistry objects such as the Red Rectangle. For oxygen-rich CSEs, which might be expected to contain methanol, Marvel (2005) estimated an upper limit of the abundance of methanol to be $4.5 \mathrm{ppb}$ and Nejad \& Millar (1988) predicted a detectable abundance of methanol. Charnley et al. (1995) have claimed that circumstellar methane could initiate ion-molecule chemistry in oxygenrich envelopes, yielding significant abundances of $\mathrm{C}_{2} \mathrm{H}_{4}, \mathrm{C}_{2} \mathrm{H}_{2}$ and $\mathrm{CH}_{3} \mathrm{OH}$. However, observationally, an initial report of methanol detection in the carbon-rich CSE IRC $+10^{\circ} 216$ has not been confirmed (Latter \& Charnley 1996) and methanol maser emission from IRAS $19312+1950$, once thought to be a mass-losing evolved star, is now considered to emanate from an accreting, high-mass young stellar object (Cordiner et al. 2016). A significant recent development is the ALMA detection of methanol in the post-AGB object HD 101584 (Olofsson et al. 2017), but this emission and that of other smaller molecules is confined to two extreme velocity spots which lie on either side of the object. Olofsson et al. propose 
that the detected molecules arise from post-shock chemistry, and interestingly in the context of our work, where circumstellar dust grains play a role. Rather than CSEs, we consider that the methanol reactions on bare silicate grains studied here are likely of more general significance in hot molecular cores, protoplanetary disks and shocked regions.

\subsection{Hot molecular cores}

In cold prestellar objects methanol is a common molecule seen in grain ice mantles through its IR absorption (Boogert et al. 2015; van Dishoeck 2014) together with IR signatures of silicates in amorphous form (Boogert et al. 2015; van Dishoeck 2014, Henning 2010). In hot molecular cores (Millar \& Hatchell 1998; Nomura \& Millar 2004; Garrod \& Weaver 2013) heating of the ices as the YSO develops results in gas-phase methanol (Maret et al. 2005; Öberg et al. 2010). Annealing of amorphous silicates to form crystalline forsterite can occur due to heating or shocks as evidenced through sharp solid-state emission features at 10.0, 11.3, 16.3, 23.5, 27.5 and $33.5 \mu \mathrm{m}$ (see Henning 2010) and in one instance these bands have been seen in absorption (Poteet et al. 2011). These features as are also seen in emission in comets (Crovisier et al. 1997). PAHs are are commonly seen in emission when pumped with UV/visible radiation in more evolved objects (see Tielens 2008).

\subsection{Protoplanetary disks}

Although gas-phase methanol is present initially as a result of ice mantle evaporation or shocks in the early stages of star formation, methanol and larger complex organic molecules 
are not generally detected in innermost hotter regions of protoplanetary disks. However, there are major observational challenges due to the small physical size of this region. Exceptions to date are detection with ALMA of $\mathrm{CH}_{3} \mathrm{CN}$ in the disk around the Herbig Ae star MWC 480 (Öberg et al. 2015) and $\mathrm{CH}_{3} \mathrm{OH}$ in the disk of the T Tauri star T W Hya (Walsh et al. 2016; Walsh, Vissapragada \& McGee 2017). In the context of our experimental work on methanol/forsterite in which PAHs are formed, a corresponding observational search for rotational transitions of the polar 'PAH' molecule benzonitrile $\left(c-\mathrm{C}_{6} \mathrm{H}_{5} \mathrm{CN}\right)$ would be of particular interest following its recent detection in TMC-1 (McGuire et al. 2018). Our laboratory experiments additionally revealed a carbon deposit on the forsterite surface. Exposure to stellar UV radiation, cosmic rays etc. would be expected to disrupt this deposit and could be a source of large gas-phase PAHs (Tielens 2008) or amorphous organic solids (Kwok \& Zhang 2011).

\subsection{Shocks}

Shocks from supernovae and outflows create a rapid increase in temperature and disrupt grain ice mantles leading to a bare grain surface on which a hot gas-surface chemistry could proceed. J-type shocks could also be important in driving the amorphous-to-crystalline forsterite transition although can also cause grains to fragment. A well-studied example is L1157 in which methanol is detected (Burkhardt et al. 2016). 


\section{Concluding remarks}

We have described experiments which make an initial step in investigating the role of bare crystalline forsterite grain surfaces in promoting reactions of the common astrophysical molecule methanol. Experimental limitations (i.e. ability to detect signals) so far restricted the accessible temperature range and higher-sensitivity studies at lower temperatures, under ultra-high vacuum conditions and with mixtures of gases are desirable; nevertheless catalytic processes are of interest given that substantially higher temperatures are generally required for pure gas-phase neutral reactions to proceed. To be of astrophysical relevance, co-existence of methanol and crystalline forsterite is a clear prerequisite. This is most likely in molecular hot cores, inner planetary disks or shocks. Complementary observational mapping of $\mathrm{CH}_{3} \mathrm{OH}$, crystalline silicate emission (or absorption) and PAHs, and crucially linked with theoretical chemical network modelling, would help establish the significance of these types of reactions. A further area of interest would be laboratory studies of reactions of hot gas in the presence of cool forsterite grains. More speculatively, reactions of the type studied here could provide a route to some of the basic molecular ingredients for life (Gallori 2011; Martins 2011). 


\section{Acknowledgements}

The work described here was supported by a grant from the University Research Committee of the University of Hong Kong. PJS thanks the Leverhulme Trust for award of an Emeritus Research Fellowship. We thank Tom Millar, Catherine Walsh, Cecilia Ceccarelli and Claudio Codella for valuable conversations and Bin Li for his expert help in using the VASP software. 


\section{References:}

Ali, A., Sittler, E.C., Chornay, D., Rowe, B., Puzzarini, C. 2013, Planet. Space. Sci., 87, 96

Anders, E., Hayatsu, R., Studier, M.H. 1973, Science 182, 781

Anders, E., Hayatsu, R., Studier, M.H. 1974, ApJ. 192, L101

Boogert, A.C.A., Gerakines, P.A., Whittet, D.C.B. 2015, ARA\&A 53, 541

Burkhardt, A.M., Dollhopf, N.M., Corby, J.F., Carroll, P.B., Shingledecker, C.N., Loomis, R.A., Booth, S.T., Blake, G.A., Herbst, E., Remijan, A.J., McGuire, B.A. 2016, ApJ. 827,21

Charnley, S., Tielens, A.G.G.M., Kress, M. 1995, Mon. Not. R. Astron. Soc. 274, L53

Cordiner, M.A., Boogert, A.C.A., Charnley, S.B., Justtanont, K., Cox, N.L.J., Smith, R.G., Tielens, A.G.G.M., Wirström, E.S., Milam, S.N., Keane, J.V. 2016, ApJ. 828, 51

Crovisier, J., Leech, K., Bockelée-Morvan, D., Brooke, T.Y., Hanner, M.S., Altieri, B., Keller, H.U., Lellouch, E. 1997, Science 275, 1904

Fahr, A., Laufer, A.H., 2005, J. Phys. Chem. A 109, 2534

Ferrante, R., Moore, M., Nuth, J., Smith, T. 2000, Icarus 145, 297

Gallori, E. 2011, Rendiconti. Lincei. 22, 113

Garrod, R.T., Weaver, S.L.W. 2013, Chem. Rev. 113, 8939

Gavilan, L., Lemaire, J. L., Vidali, G., Sabri, T., Jäger, C. 2014, ApJ. 781, 79.

Guo, Y.H. Xia, C., Liu, B.S., 2014, Chem. Eng. J. 237, 421

Henning, Th. 2010, ARA\&A 2010, 48, 21

Herbst, E. 2005, ESA Special Publication 577, 205

Herbst, E., Chang, Q., Cuppen, H. 2005, J. Phys. Conf. Ser. 6, 18

Herbst, E., van Dishoeck, E.F. 2009, Annu. Rev. Astron. Astrophys. 47, 427

Herbst, E. 2017, Int. Rev. Phys. Chem. 36, 287

Huang, X., Lee, T.J., 2011, ApJ., 736, 33

Kress, M.E., Tielens, A.G.G.M. 2001, Meteorit. Planet. Sci. 36, 75

Kresse, G., Hafner, J. 1993, Phys. Rev. B. 48, 13115

Kresse, G., Furthmüller, J. 1996, Comput. Mater. Sci. 6, 15

Kwok, S., Zhang, Y. 2011, Nature, 479, 80

Latter, W.B., Charnley, S. 1996, ApJL. 463, L37

Li, J., Qi, Y., Liu, Z., Liu, G., Zhang, D. 2008, Catal. Lett. 121, 303 
Liu, B.S., Zhang, Y., Liu, J.F., Tian, M., Zhang, F.M., Au, C.T., Cheung, A.S.-C. 2011, J. Phys. Chem. C. 115, 16954

Maret, S., Ceccarelli, C., Tielens, A.G.G.M., Caux, E., Lefloch, B., Faure, A., Castets, A., Flower, D. 2005, A\&A 442, 527

Martins, Z. 2011, Elements, 7, 35

Marvel, K.B. 2005. AJ. 130, 261

McGuire, B.A., Burkhardt, A.M., Kalenskii, S., Shingledecker, C.N., Remijan, A.J., Herbst, E., McCarthy, M.C. 2018, Sci. 359, 202

Millar, T.J. \& Hatchell, J. 1998, Faraday Discussions, 109, 15

Minh, Y.C., van Dishoeck, E.F. 2000, In Astrochemistry: from molecular clouds to planetary systems, Proceedings of IAU Symposium 197

Nejad L., Millar, T. 1988, Mon. Not. R. Astron. Soc. 230, 79

Nomura, H., Millar, T.J. 2004, A\&A. 414, 409

Öberg, K.I., Bottinelli, S., Jørgensen, J.K., van Dishoeck, E.F. 2010, ApJ 716, 82519

Öberg, K. I., Guzmán, V. V., Furuya, K., Qi, C., Aikawa, Y., Andrews, S.M., Loomis, R., Wilner, D.J. 2015, Nat. 520, 198

Olofsson, H., Vlemmings, W.H.T., Bergman, P., Humphreys, E.M.L., Lindqvist, M., Maercker, M., Nyman, L., Ramstedt, S., Tafoya, D. 2017, A\&A 603, L2

Poteet, C.A., Megeath, S.T., Watson, D.M., Calvet, N., Remming, I.S., McClure, M.K., Sargent, B.A., Fischer, W.J., Furlan, E., Allen, L.E., Bjorkman, J.E., Hartmann, L., Muzerolle, J., Tobin, J.J., Ali, B. 2011, ApJL. 733, L3

Ricks, A.M., Douberly, G.E., Schleyer, P. v. R., Duncan, M.A., 2010, J. Chem. Phys., 132,051101

Sabri, T., Gavilan, L., Jäger, C., Lemaire, J. L., Vidali, G., Mutschke, H., Henning, T. 2014, ApJ. 780, 180

Schlemmer, S., Giesen, T., Mutschke, H. 2014, Laboratory astrochemistry: from molecules through nanoparticles to grains, pub. John Wiley \& Sons.

Sturm, B., Bouwman, J., Henning, Th., Evans II, N.J., Waters, L. B. F. M., van Dishoeck, E.F. Green, J.D., Olofsson, J., Meeus, G., Maaskant, K., Dominik, C., Augereau, J.C., Mulders, G.D., Acke, B., Merin, B., Herczeg, G.J. and The DIGIT team, 2013, A\&A, A5 
Tian, M., Liu, B.S., Hammonds, M., Wang, N., Sarre, P.J., Cheung, A.S.-C. 2012. Phys. Chem. Chem. Phys.14, 6603

Tian, M., Liu, B.S., Hammonds, M., Wang, N., Sarre, P.J., Cheung, A.S.-C. 2013. Phil. Trans. R. Soc. A. 371, 20110590

Tielens, A.G.G.M. 2008, Annu. Rev. Astron. Astrophys. 46, 289

Tielens, A.G.G.M. 2013, Rev. Mod. Phys. 85, 1021

van Dishoeck, E.F. 2014, Farad. Discuss. 168, 9

Wakelam, V., Bron, E., Cazaux, S., Dulieu, F., Gry, C., Guillard, P., Habart, E., Hornekær, L., Morisset, S., Nyman, G., Pirronello, V., Price, S.D., Valdivia, V., Vidali, G., Watanabe, N., 2017, MolAs. 9, 1

Walsh, C., Loomis, R.A., Öberg, K.I., Kama, M., van't Hoff, M.L.R., Millar, T.J., Aikawa, Y., Herbst, E., Widicus Weaver, S.L., Nomura, H., 2016, ApJL, 823, L10 Walsh, C., Vissapragada, S., McGee, H. 2017, eprint arXiv:1710.01219

Williams, D.A, Cecci-Pestellini, C. 2016, The Chemistry of Cosmic Dust, (Cambridge, Royal Society of Chemistry)

Zhao, D., Doney, K.D., Linnartz, H. 2014, ApJ. 791, L28

Zhao, T.Q., Li, Q., Liu, B.S., Gover, R.K.E., Sarre, P.J., Cheung, A.S.-C. 2016. Phys. Chem. Chem. Phys. 18, 3489 


\section{Figure captions:}

Figure 1 TOF-MS spectra of catalytic conversion of methanol over forsterite at $550^{\circ} \mathrm{C}$ with different times on-stream. The numerical values are the molecular weights of the organic molecules and PAHs formed. The vertical scale for $m / z>75$ is x5.

Figure 2 Comparison of the products formed as a function of time. The numerical values are the molecular weights of the organic compounds and PAHs formed.

Figure 3 TOF-MS spectra of (a) methanol and (b) methanol-d4 conversion over forsterite at $600^{\circ} \mathrm{C}$ for 10 minutes after the start of the reaction. For $\mathrm{m} / \mathrm{z}$ signals $>90$, the spectra have been scaled up by a factor 2 (see text).

Figure 4. HRTEM images and TG/DTG profiles of the carbon deposition on the forsterite surface after the reaction.

Figure 5 FT-IR spectra of methanol adsorbed on the forsterite surface: (a) pure solid particles with no methanol, (b and c) forsterite particles exposed to 0.35 or 1.8 bar of methanol, respectively, and (d) forsterite exposed to saturated methanol vapour (the number in parentheses is the vibrational frequency (wavenumber) for gas-phase methanol).

Scheme 1. Methanol adsorbed on the (100) plane of $\mathrm{Fe}_{2}$ (or $\left.\mathrm{Mg}_{2}\right) \mathrm{SiO}_{4}$ with five configurations. The main atoms are labelled in colour: (Fe (or $\mathrm{Mg}$ ) is gold, $\mathrm{Si}$ in blue, $\mathrm{O}$ in red, $\mathrm{C}$ in brown, $\mathrm{H}$ in pink).

Scheme 2. Proposed reaction mechanism for catalytic conversion of methanol in forming olefins and water.

Scheme 3. Proposed reaction mechanism for catalytic conversion of methanol in forming $\mathrm{CO}_{2}$ (or $\mathrm{CO}$ ). 
Table legends:

Table 1. A summary of carbon compounds observed from the catalytic conversion of methanol on forsterite.

Table 2. Calculated adsorption energy and the bond length of the $\mathrm{O}-\mathrm{H}$ and $\mathrm{C}-\mathrm{O}$ bonds of methanol on the (100) plane of $\mathrm{Fe}_{2} \mathrm{SiO}_{4}$ and $\mathrm{Mg}_{2} \mathrm{SiO}_{4}$ for all five configurations. 


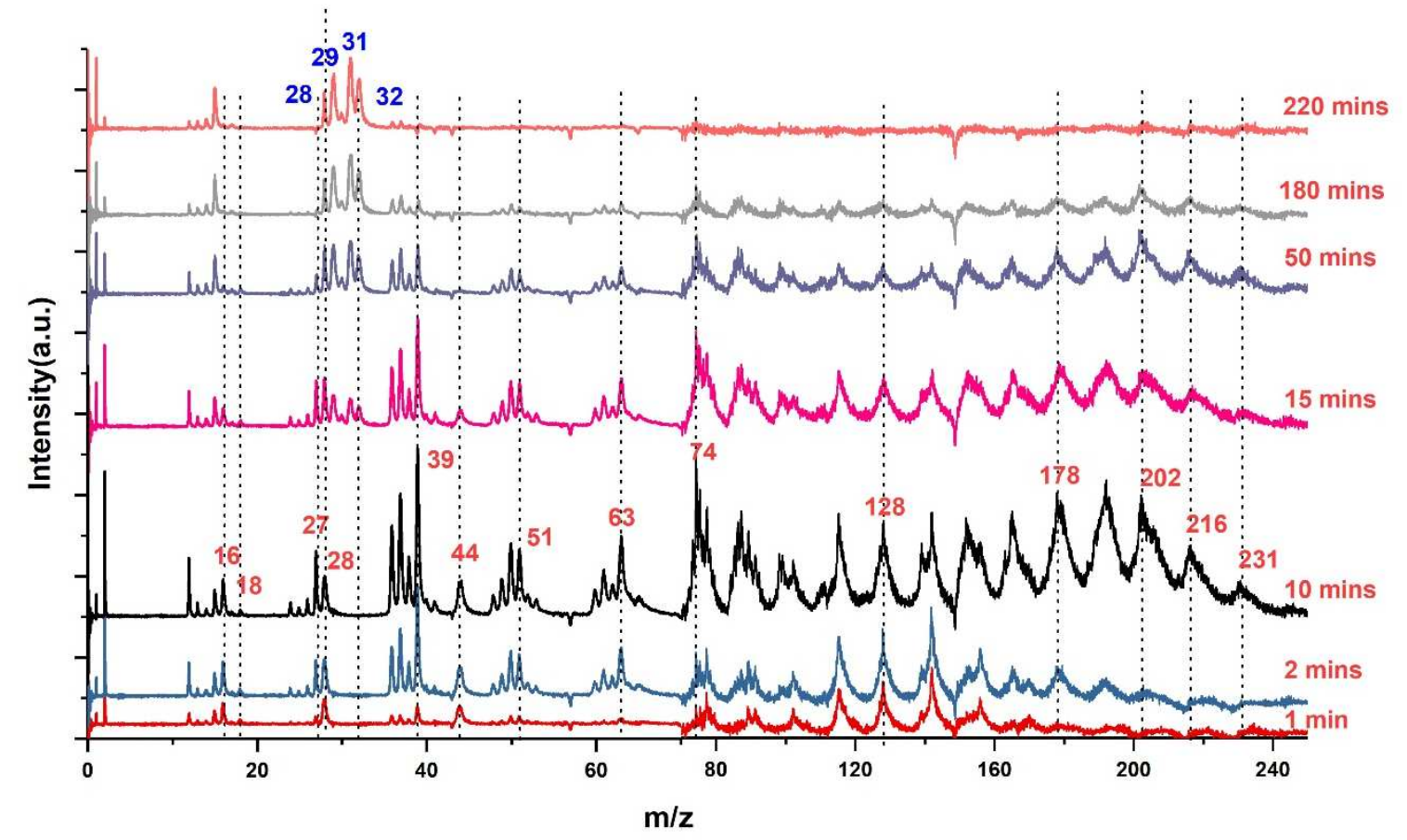

\section{Figure 1}

TOF-MS spectra of catalytic conversion of methanol over forsterite at $550{ }^{\circ} \mathrm{C}$ with different times on-stream. The numerical values are the molecular weights of the organic molecules and PAHs formed. The vertical scale for $\mathrm{m} / \mathrm{z}>75$ is $\mathrm{x} 5$. 


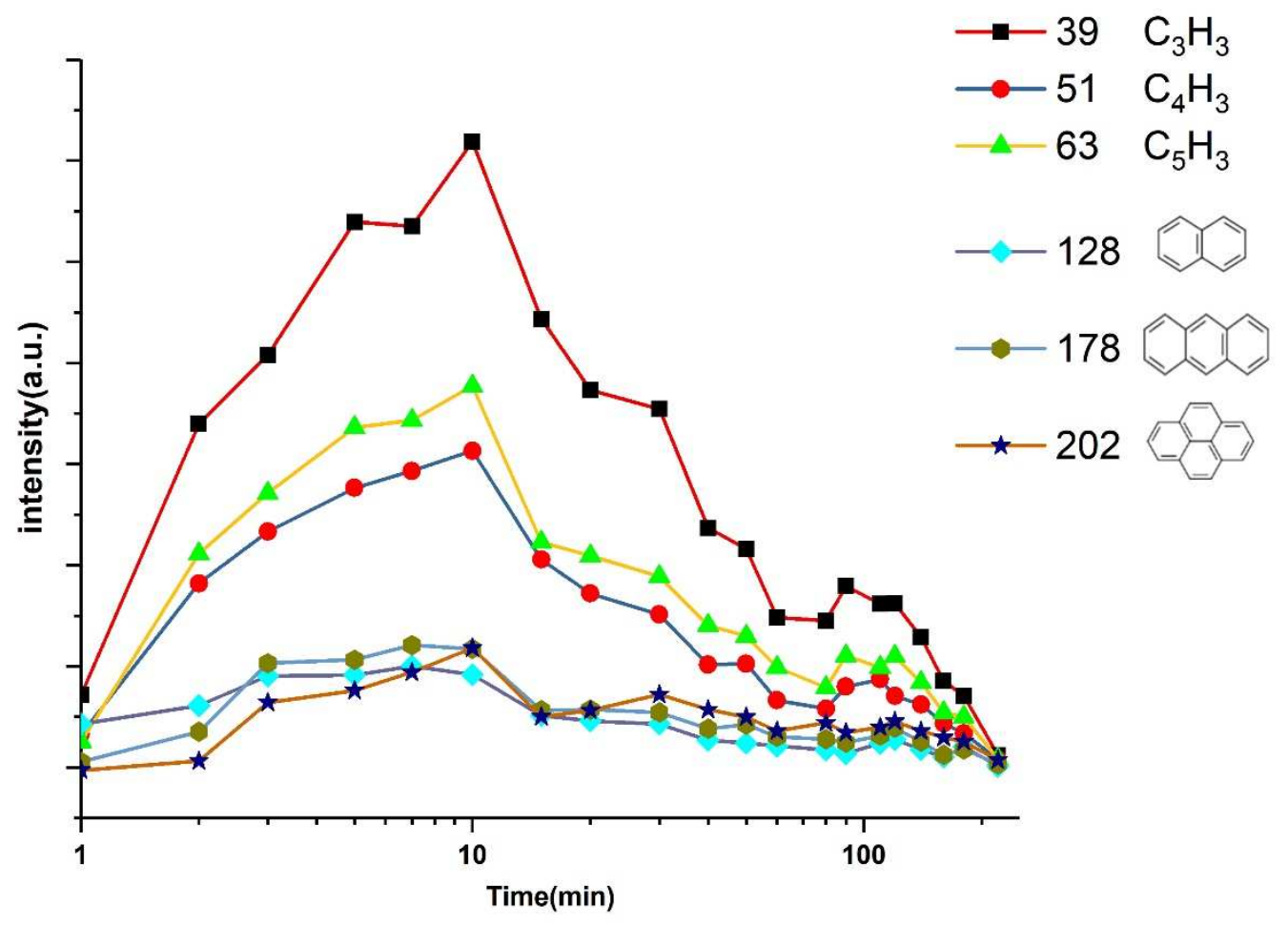

Figure 2

Comparison of the products formed as a function of time. The numerical values are the molecular weights of the organic compounds and PAHs formed. 


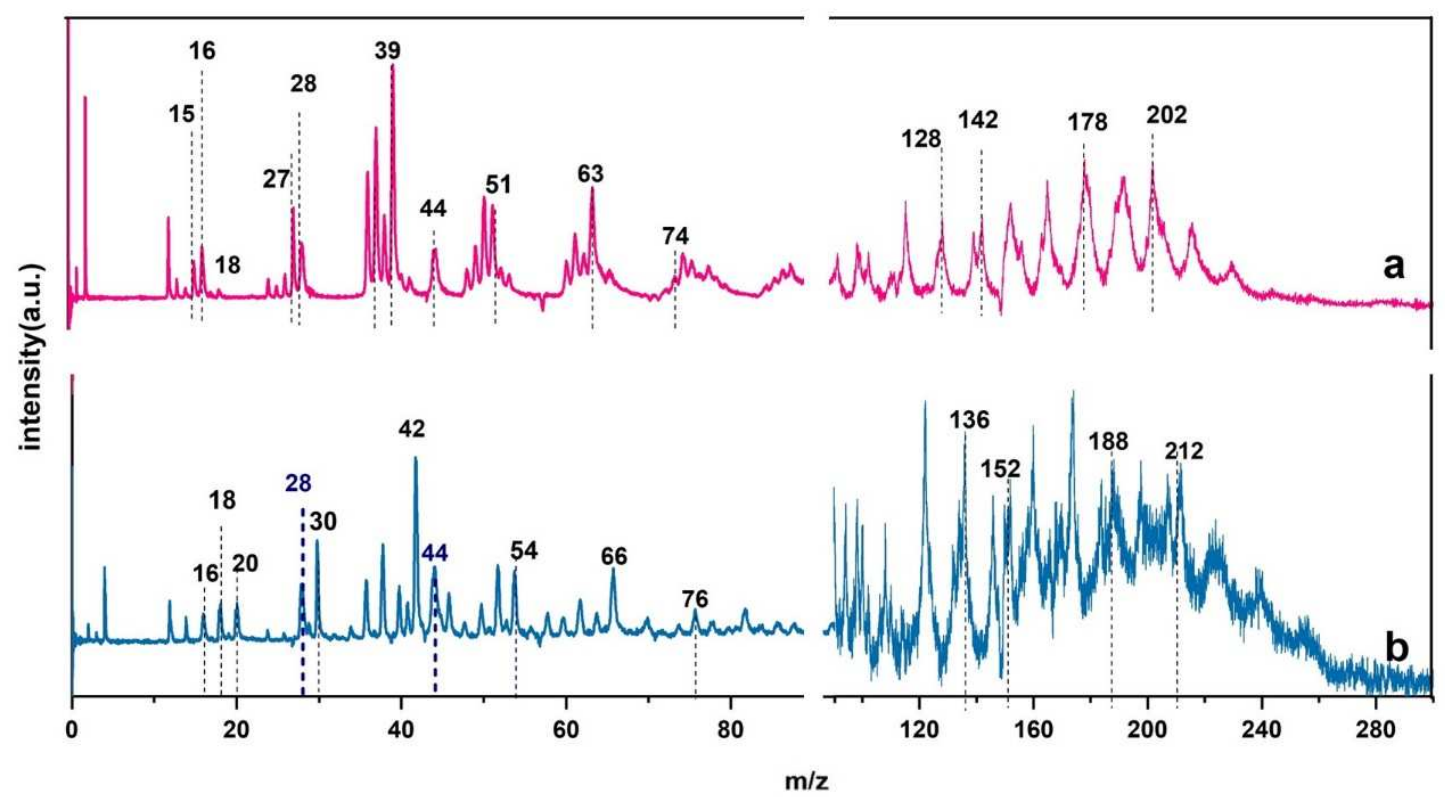

Figure 3 TOF-MS spectra of (a) methanol and (b) methanol-d4 conversion over forsterite at $600^{\circ} \mathrm{C}$ for 10 minutes after the start of the reaction. For $\mathrm{m} / \mathrm{z}$ signals $>90$, the spectra have been scaled up by a factor 2 (see text). 


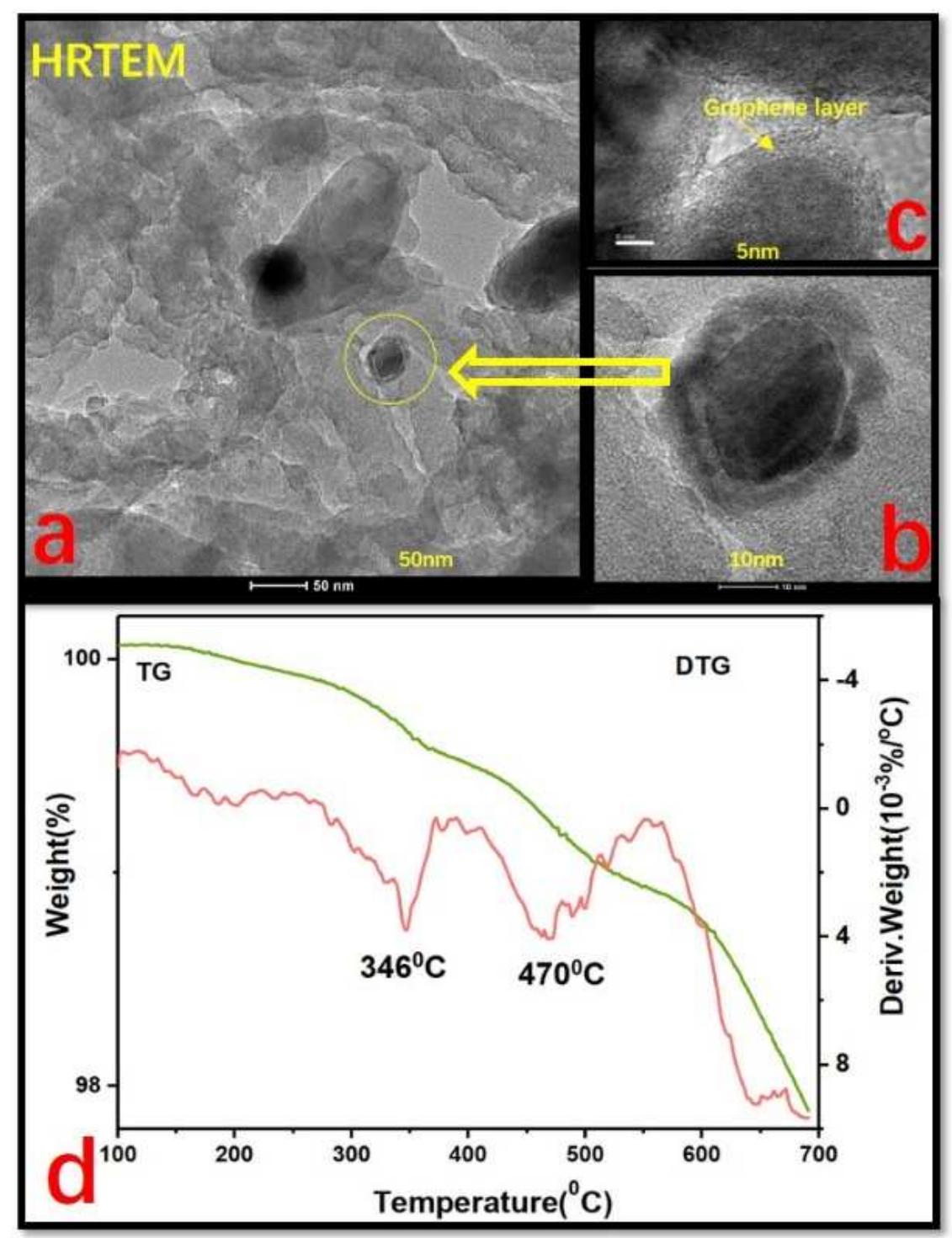

Figure 4 HRTEM images and TG/DTG profiles of the carbon deposition on forsterite surface after the reaction. 


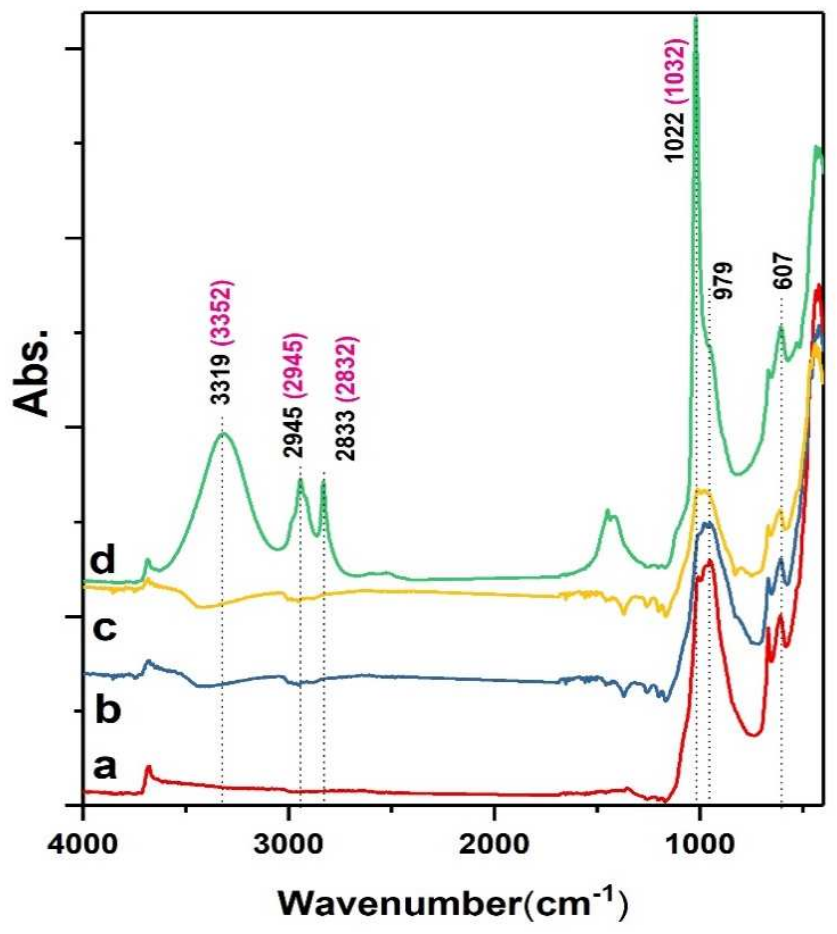

Figure 5 FT-IR spectra of methanol adsorbed on the forsterite surface: (a) pure solid particles with no methanol, $(\mathrm{b}, \mathrm{c})$ forsterite particles exposed to 0.35 or 1.8 bar of methanol, respectively, and (d) forsterite exposed to saturated methanol vapour (the number in parentheses is the gas-phase vibrational frequency (wavenumber) for gasphase methanol). 


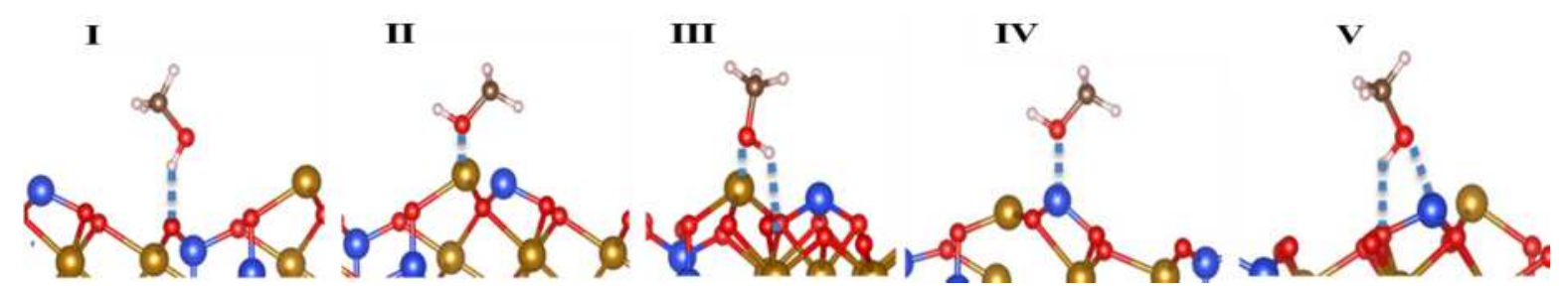

Scheme 1. Methanol adsorbed on the (100) plane of $\mathrm{Fe}_{2}\left(\right.$ or $\left.\mathrm{Mg}_{2}\right) \mathrm{SiO}_{4}$ with five configurations. The main atoms are labelled in colour: ( $\mathrm{Fe}$ (or $\mathrm{Mg}$ ) is gold, $\mathrm{Si}$ in blue, $\mathrm{O}$ in red, $\mathrm{C}$ in brown, $\mathrm{H}$ in pink). 


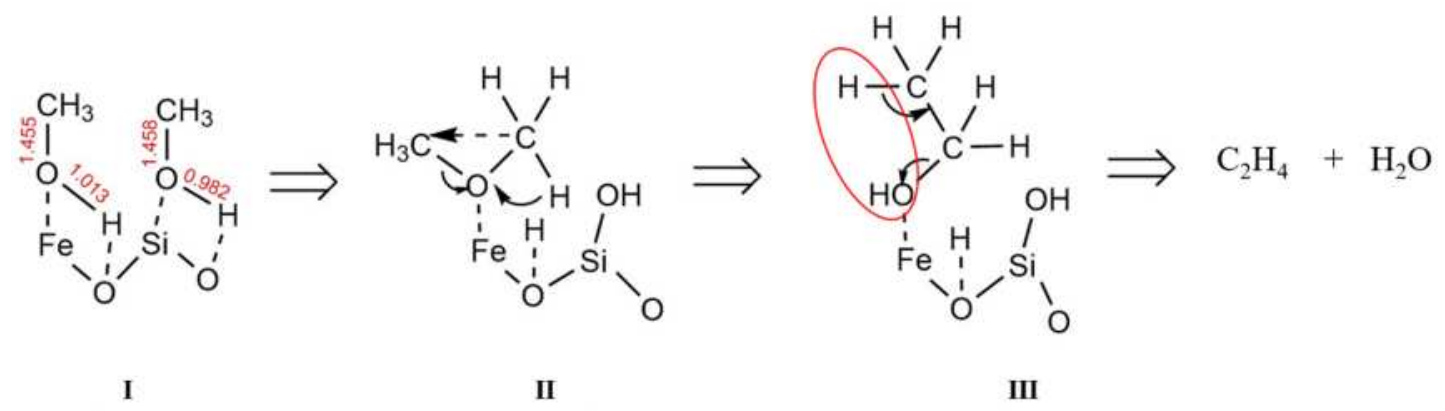

Scheme 2. Proposed reaction mechanism for catalytic conversion of methanol in forming olefins and water. 


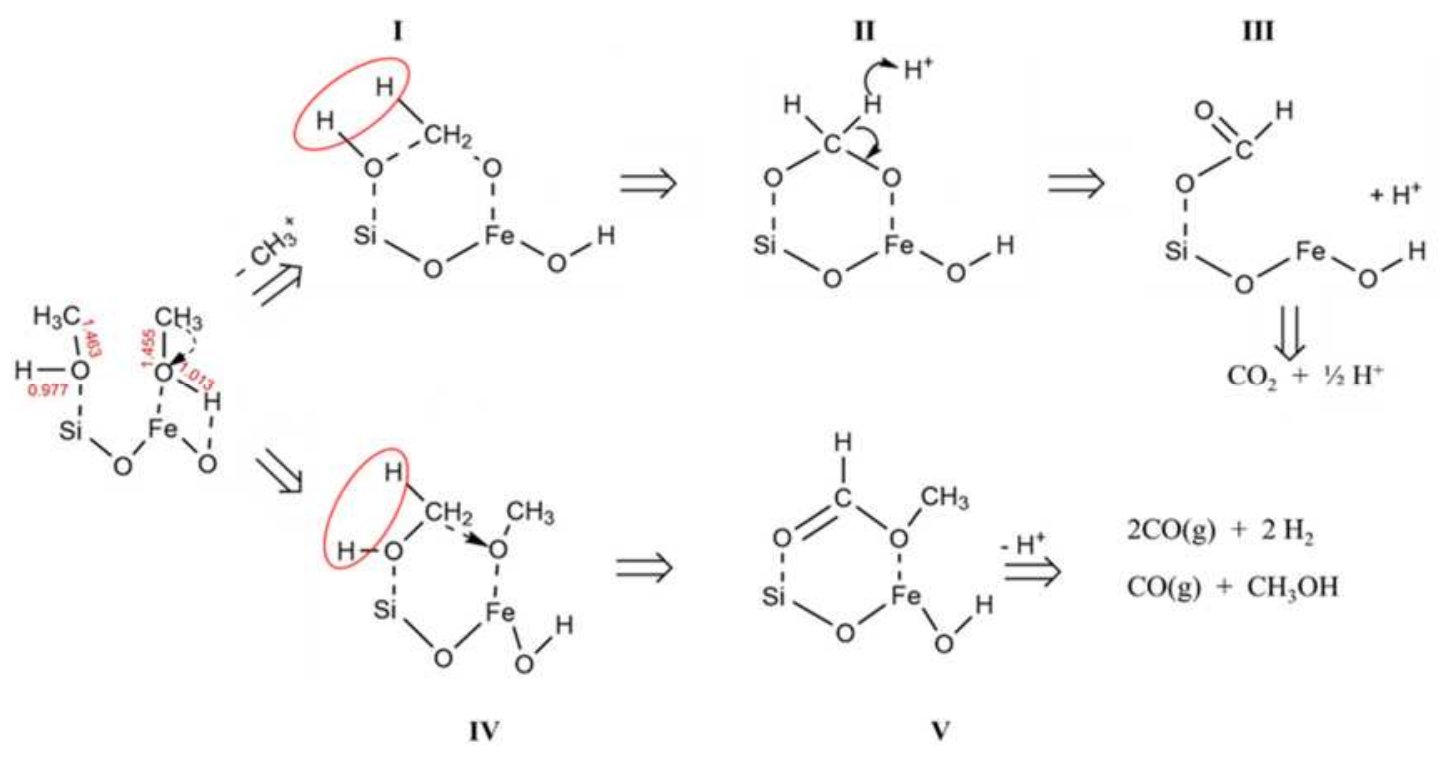

Scheme 3. Proposed reaction mechanism for catalytic conversion of methanol in forming $\mathrm{CO}_{2}$ (or $\mathrm{CO}$ ). 
Table 1. Summary of carbon compounds observed from the catalytic conversion of methanol on forsterite.

\begin{tabular}{|c|c|c|c|c|c|}
\hline Compound & $\begin{array}{l}\text { Molecular mass } \\
\text { from methanol }\end{array}$ & $\begin{array}{l}\text { molecular mass from } \\
\text { methanol-d4 }\end{array}$ & Compound & $\begin{array}{l}\text { Molecular mass } \\
\text { from methanol }\end{array}$ & $\begin{array}{l}\text { molecular mass from } \\
\text { methanol-d4 }\end{array}$ \\
\hline $\mathrm{H}$ & 1 & 2 & $\mathrm{C}_{4}$ & 48 & 48 \\
\hline $\mathrm{H}_{2}$ & 2 & 4 & $\mathrm{C}_{4} \mathrm{H}$ & 49 & 59 \\
\hline $\mathrm{C}$ & 12 & 12 & $\mathrm{C}_{4} \mathrm{H}_{2}$ & 50 & 52 \\
\hline $\mathrm{CH}$ & 13 & 14 & $\mathrm{C}_{4} \mathrm{H}_{3}$ & 51 & 54 \\
\hline $\mathrm{CH}_{2}$ & 14 & 16 & $\mathrm{C}_{4} \mathrm{H}_{4}$ & 52 & 56 \\
\hline $\mathrm{CH}_{3}$ & 15 & 18 & $\mathrm{C}_{5}$ & 60 & 60 \\
\hline $\mathrm{O}$ & 16 & 16 & $\mathrm{C}_{5} \mathrm{H}$ & 61 & 62 \\
\hline $\mathrm{H}_{2} \mathrm{O}$ & 18 & 20 & $\mathrm{C}_{5} \mathrm{H}_{2}$ & 62 & 64 \\
\hline $\mathrm{C}_{2}$ & 24 & 24 & $\mathrm{C}_{5} \mathrm{H}_{3}$ & 63 & 66 \\
\hline $\mathrm{C}_{2} \mathrm{H}$ & 25 & 26 & $\mathrm{C}_{6} \mathrm{H}_{2}$ & 74 & 76 \\
\hline $\mathrm{C}_{2} \mathrm{H}_{2}$ & 26 & 28 & $\mathrm{C}_{7} \mathrm{H}_{2}$ & 86 & 88 \\
\hline $\mathrm{C}_{2} \mathrm{H}_{3}$ & 27 & 30 & $\mathrm{C}_{8} \mathrm{H}_{2}$ & 98 & 100 \\
\hline $\mathrm{CO} / \mathrm{C}_{2} \mathrm{H}_{4}$ & 28 & $28 / 32$ & $\mathrm{C}_{8} \mathrm{H}_{6}$ & 102 & 108 \\
\hline $\mathrm{CHO}$ & 29 & 30 & $\mathrm{C}_{9} \mathrm{H}_{7}$ & 115 & 122 \\
\hline $\mathrm{CH}_{2} \mathrm{O}$ & 30 & 32 & $\mathrm{C}_{10} \mathrm{H}_{8}$ & 128 & 136 \\
\hline $\mathrm{CH}_{3} \mathrm{O}$ & 31 & 34 & $\mathrm{C}_{11} \mathrm{H}_{7}$ & 139 & 146 \\
\hline $\mathrm{CH}_{3} \mathrm{OH}$ & 32 & 36 & $\mathrm{C}_{11} \mathrm{H}_{10}$ & 142 & 152 \\
\hline $\mathrm{C}_{3}$ & 36 & 36 & $\mathrm{C}_{12} \mathrm{H}_{8}$ & 152 & 160 \\
\hline $\mathrm{C}_{3} \mathrm{H}$ & 37 & 38 & $\mathrm{C}_{13} \mathrm{H}_{9}$ & 165 & 174 \\
\hline $\mathrm{C}_{3} \mathrm{H}_{2}$ & 38 & 40 & $\mathrm{C}_{14} \mathrm{H}_{10}$ & 178 & 188 \\
\hline $\mathrm{C}_{3} \mathrm{H}_{3}$ & 39 & 42 & $\mathrm{C}_{15} \mathrm{H}_{12}$ & 192 & 204 \\
\hline $\mathrm{C}_{3} \mathrm{H}_{5}$ & 41 & 46 & $\mathrm{C}_{16} \mathrm{H}_{10}$ & 202 & 212 \\
\hline $\mathrm{CO}_{2} / \mathrm{CH}_{3} \mathrm{COH}$ & 44 & $44 / 48$ & $\mathrm{C}_{17} \mathrm{H}_{12}$ & 216 & 228 \\
\hline
\end{tabular}


Table 2. Calculated adsorption energies and lengths of $\mathrm{O}-\mathrm{H}$ and $\mathrm{C}-\mathrm{O}$ bonds of methanol on the (100) plane of $\mathrm{Fe}_{2} \mathrm{SiO}_{4}$ and $\mathrm{Mg}_{2} \mathrm{SiO}_{4}$ for all five configurations.

\begin{tabular}{|c|c|c|c|c|c|c|c|}
\hline & & \multicolumn{3}{|c|}{$\mathrm{Fe}_{2} \mathrm{SiO}_{4}$} & \multicolumn{3}{|c|}{$\mathrm{Mg}_{2} \mathrm{SiO}_{4}$} \\
\hline & & $\begin{array}{c}\underline{\mathrm{E}}_{\mathrm{ads}} \\
\mathrm{\textrm {kJ }} / \mathrm{mol} \\
\end{array}$ & $\frac{\mathrm{r}(\mathrm{O}-\mathrm{H})}{\underline{\AA}}$ & $\frac{\mathrm{r}(\mathrm{C}-\mathrm{O})}{\underline{\AA}}$ & $\begin{array}{c}\underline{\mathrm{E}}_{\mathrm{ads}} \\
\mathrm{kJ} / \mathrm{mol}\end{array}$ & $\frac{\mathrm{r}(\mathrm{O}-\mathrm{H})}{\underline{\AA}}$ & $\frac{\mathrm{r}(\mathrm{C}-\mathrm{O})}{\underline{\AA}}$ \\
\hline \multicolumn{2}{|c|}{ Experimental $^{43}$} & - & 0.956 & 1.427 & - & 0.956 & 1.427 \\
\hline \multicolumn{2}{|c|}{ "No/weak interaction" } & - & 0.972 & 1.432 & - & 0.971 & 1.432 \\
\hline \multirow{5}{*}{ Interaction } & $\mathbf{I}$ & 16.9 & 0.981 & 1.419 & 46.3 & 0.992 & 1.413 \\
\hline & II & 57.1 & 0.973 & 1.447 & 54.1 & 0.969 & 1.440 \\
\hline & III & 73.5 & 1.013 & 1.455 & 55.8 & 0.978 & 1.436 \\
\hline & IV & 102.5 & 0.977 & 1.463 & 77.8 & 0.981 & 1.470 \\
\hline & $\mathbf{V}$ & 183.8 & 0.982 & 1.458 & 135.6 & 0.988 & 1.447 \\
\hline
\end{tabular}

Notes: the bond length of the "no interaction" case is averaged among the results of all 5 models. 